This work is licensed under a Creative Commons Attribution 4.0 International License https://creativecommons.org/licenses/by/4.0/

DOI: $10.24833 / 2410-2423-2021-1-25-15-26$

\title{
STYLISTIC FEATURES OF DIPLOMATIC TEXTS IN CZECH
}

\author{
N.V. Davletshina \\ Moscow State Institute of International Relations (University) \\ 76, Prospect Vernadskogo, Moscow, 119454, Russia
}

\begin{abstract}
The current article is devoted to the analysis and description of the language of a modern diplomatic text, which represents a diplomatic substyle of a business style. In the Czech language, which possesses a wide stylistic differentiation, a diplomatic substyle remains insufficiently studied. A diplomatic substyle is an integral part of the language of diplomatic communication, in which the Heads of the State and the Government, the ministers of foreign affairs, and representative institutions are involved. This fact brings it closer to the language of political communication.

For this reason, the author aims at characterizing the stylistic features of traditional text types in the diplomatic correspondence between the Czech Republic and the Russian Federation, and highlighting their similarities and differences in form as well as in content. By the example of original texts the structure of a diplomatic document is represented: a form of address, protocol forms of courtesy and compliments, its semantic core and the argumentation part as essential parts of a document.

The fore cited analysis of the functional-communicative features of the diplomatic texts lexical composition shows the presence of professional names and terms, idioms and cliché, as well as new lexical units and terms that reflect socio-political changes in the Czech Republic and new geopolitical realities.
\end{abstract}

Key Words: the Czech language, diplomatic correspondence, protocol practise, a note verbal, a circular note, personal semi-formal letters and telegrams, new types of diplomatic documents

For citation: Davletshina N.V. 2021. Stylistic Features of Diplomatic Texts in Czech. Philological Sciences at MGIMO.Vol. 7. No 1(25). P. 15-26. https://doi.org/10.24833/2410-2423-2021-1-25-15-26

\section{СТИЛИСТИЧЕСКИЕ ОСОБЕННОСТИ ДИПЛОМАТИЧЕСКИХ ТЕКСТОВ НА ЧЕШСКОМ ЯЗЫКЕ}

\author{
Н.В. Давлетшина
}

Московский государственный институт международных отношений (университет) МИД России 119454, Россия, Москва, пр.Вернадского, 76. 
Аннотация. Настоящая статья посвящена анализу и описанию языка современного дипломатического текста на чешском языке, представляющего собой деловой стиль, составной частью которого является дипломатический подстиль. В чешском языке, имеющем широкую смысловую дифференииацию, дипломатический подстиль остаётся недостаточно изученным. Он характерен для языка дипломатической коммуникации как языка официального межгосударственного общения, в котором участвуют главы государств и правительств, министрь иностранных дел, представительские учреждения, что сближает его с языком политической коммуникаиии. Поэтому основное внимание автор уделяет характеристике стилистических особенностей традиционньх видов текстов в дипломатической переписке между Чехией и Россией, а также текстов устных выступлений государственных деятелей и дипломатических представителей Чешской Республики, выделяет их общие и отличительные черты как по форме, так и по содержанию. На примере оригинальных текстов представлена структура дипломатического документа: форма обращения, протокольнье формуль вежливости и комплименты, его смысловое ядро и аргументаиионная часть. Приведённый в статье анализ функицонально-коммуникативных особенностей лексического состава дипломатических текстов показывает наличие в них профессиональных названий и терминов, фразеологических оборотов и клише, в том числе новых лексических единиц и терминов, отражающих общественнополитические изменения в Чешской Республике и новые геополитические реалии.

Ключевые слова: чешский язык, дипломатическая переписка, протокольная практика, вербальные и циркулярные ноты, тичные письма полуобиииального характера и телеграммы, новые виды дипломатических документов

Для цитирования: Давлетшина Н.В. 2021. Стилистические особенности дипломатических текстов на чешском языке. Филологические науки в МГИМО. Том 7. № 1(25). С. 15-26. https://doi. org/10.24833/2410-2423-2021-1-25-15-26

$\mathrm{B}$ терминологическом словаре О.С. Ахмановой стиль характеризуется как «одна из дифференциальных разновидностей языка, языковая подсистема со своеобразным словарём, фразеологическими сочетаниями, оборотами и конструкциями, ...обычно связанная с определёнными сферами употребления речи [1, с. 455]. Известные чешские лингвисты Ф. Травничек и Б. Гавранек связывали стилевую дифференциацию чешского языка исключительно с текстами на чешском литературном языке, как языке, имеющем общенациональный статус [3, с. 346-347; 17, с. 45-46].

Среди функциональных стилей литературного чешского языка выделяется деловой стиль, основу которого составляют языковые средства, типичные для данной функционально-коммуникативной сферы. Его составной частью является дипломатический подстиль, функционирующий в сфере межгосударственного общения (общественное управление, экономика, судопроизводство и др.). Он характеризуется прежде всего специфическим набором лексических средств, которые состоят из специальных (профессиональных) названий и терминов $[8$, с. 9].

Определение понятия «дипломатический язык» связано, главным образом, с именами таких видных советских учёных и дипломатов, как Ковалёв А.Н. и Кузьмин Э.Л. Они рассматривали язык дипломатии, на котором ведутся международные переговоры и составляются дипломатические документы, в двух значениях. С одной стороны, это язык официальных дипломатических сношений, с другой - совокупность специальных терминов и фраз, образующая общепринятый в мире дипломатии словарь [5, с. 66; 6, с. 135].

В книге «Энциклопедия дипломатии» чешский исследователь и дипломат В. Губинер рассматривает понятие «дипломатии» в широком смысле как встречи и контакты на международном уровне, а в узком смысле - как осуществление внешней политики государства прежде всего высшими государственными деятелями, внешнеполитическими и дипломатическими учрежде- 
ниями. Вместе с тем автор подчёркивает, что дипломатия - это не политика, а инструмент для осуществления политики государства [11, s. 42-43]. Развивая эту мысль, известный чешский профессор В. Оутрата определяет дипломатию как метод внешней политики, направленный на достижение поставленных целей путём переговоров [15, s. 11]. Такую же позицию разделяет О. Крейчи, который в книге «Международная политика» под дипломатией понимает одновременно профессию и инструмент дипломата [14, s. 335]. Из этих определений следует, что в языке дипломатического общения находят своё отражение содержание и сущность дипломатической деятельности государства, которая включает как личные контакты и переговоры, так и обмен дипломатическими документами.

Получателем и отправителем дипломатической корреспонденции может быть глава государства, председатель правительства, министр иностранных дел, представительские учреждения. Учитывая различные формы взаимоотношений между государствами на современном этапе, в дипломатической переписке могут участвовать и другие правительственные органы (министерство обороны, торговли) по согласованию с правительством или министром иностранных дел. Дипломатические тексты в переписке между Чехией и Россией могут быть составлены на чешском или русском языках, но с последующим неофициальным переводом на язык другой страны.

Поскольку дипломатические документы представляют собой официальные документы данного государства, то к языку и стилю дипломатических текстов предъявляются высокие требования: каждая фраза в них должна соответствовать тому содержанию, которое в неё вкладывается. А.Н. Ковалёв справедливо отмечает: «В умении понять других, проникнуть в образ мышления и психологию народа, живущего в иных общественных условиях, - первый залог того, что в дипломатическом документе будет найден общий язык с теми, к кому обращён этот дипломатический документ» $[5$, с. 113].

Наиболее распространённой формой обращения в чешском языке является pan, paní - господин, госпожа. Оно используется как в повседневном общении, так и на официальном уровне. К коллегам по работе принято обращение: Pane kolego; Paní kolegyně. В сочетании с ними в деловых письмах обычно употребляется vážený/vážená - уважаемый/уважаемая как нейтральная форма вежливости, далее следует имя адресата, его должность или звание.

Составной частью дипломатического этикета является правильное обращение с именами и фамилиями. Некоторые из них имеют схожее звучание и написание, учитывая близость чешского и русского языков как славянских, например: Bělohlavek a Bělohradek; есть фамилии односложные со слогообразующим согласным, например: $\mathrm{Chrz}$, Ot, Trč ; часть фамилий немецкого происхождения пишется по-немецки или имеет чешское правописание, например: Schwarz и Švarc; встречаются также фамилии словацкого, русского, украинского, русинского, венгерского, польского, французского происхождения ${ }^{1}$.

Иностранные имена и фамилии, как правило, сохраняют своё написание на языке оригинала: Donald Trump, Joe Biden, Boris Johnson, Heiko Maas, Andrzej Duda и другие.

В зависимости от служебного положения адресата, цели дипломатического документа, сложившихся традиций и уровня отношений между странами в тексте используются и соответствующие социальные нормы общения, выраженные в правилах хорошего тона, дипломатической вежливости и комплиментах. Личные ноты, частные письма полуофициального характера и телеграммы составляются автором от первого лица и начинаются с обращения: Vážený pane velvyslanče Уважаемый господин Посол; Vážený pane generální konzule - Уважаемый господин Генеральный консул; Vážený pane ministř - Уважаемый господин Министр. Здесь следует отметить, что в чешском языке, в отличие от русского языка, сохранилась особая звательная форма падежа, которая употребляется при обращении. Во множественном числе она совпадает с именительным падежом: Vážené paní a pánové - Уважаемые господа.

\footnotetext{
1 Наиболее распространёнными фамилиями в Чешской Республике являются Novák, Novotný, Svoboda, Dvořák, Černý, Kučera, Procházka [11, s. 282].
} 
В письмах и телеграммах главе правительства, руководителям парламента, министрам и послам, а также главам духовных организаций обращением может служить Vaše Excelence - Ваше Превосходительство, к ректорам высших учебных заведений - Magnificence, деканам - Spektabilis. Использование при обращении слов латинского происхождения связано с тем, что в период основания Карлова Университета в Праге в XIV веке шёл процесс заимствования латинских слов, относящихся к сфере образования, например: rektor, bakalár, magistr и другие [8, с. 305]. Обращением к Папе (Римскому), Патриарху Московскому и всея Руси является Vaše Svatosti или Svatý otče, кардиналу - Vaše Eminence или Pane Kardinale, архиепископу (епископу) - Vaše arcibiskupská (biskupská) milosti, священнику - Důstojný pane, если во главе государства стоит король - Vaše Veličenstvo - Ваше Величество. При обращении к президенту страны используется Vaše Excelence или Vážený pane prezidente. Чтобы придать документу тёплый, дружеский характер и подчеркнуть важность двусторонних отношений, к такому обращению может быть добавлено имя - Vážený pane prezidente, milý Miloši - Уважаемый господин Президент, дорогой Милош. Так обратился к чешскому президенту Генеральный секретарь Североатлантического альянса в связи с его избранием на новый срок. Подобное обращение содержится в поздравительной телеграмме французского президента - Vážený pane prezidente, drahý př́teli - Уважаемый господин Президент, дорогой друг. Такие обращения являются свидетельством более тёплой тональности телеграмм и выражают стремление авторов к дальнейшему укреплению контактов с этой страной.

Адрес в таких посланиях пишется в именительном падеже в левом нижнем углу с указанием ранга: Mimořádný a zplnomocněný velvyslanec Ruské Federace - Чрезвычайный и Полномочный Посол Российской Федерации. В ряде случаев, если в обращении содержится титул, то в адресе перед фамилией лица он также указывается: Jeho Excelence předseda vlády Ruské Federace - Его Превосходительство Председатель Правительства Российской Федерации; Její Excelence předsedkyně Rady federace Federálního shromáždění - Её Превосходительство Председатель Совета Федерации Федерального собрания.

В заключительной части содержится комплимент: S úctou, S pozdravem, S prátelským pozdravem. Письма и телеграммы в связи с траурными событиями в стране заканчиваются выражением соболезнования: Vaše Excelence, přijměte prosím naši hlubokou/upř́mnou soustrast - Ваше Превосходительство, примите, пожалуйста, наше глубокое/искреннее соболезнование [4, с. 143].

Что касается вербальной ноты, наиболее распространённого вида дипломатической переписки между Чехией и Россией, то она составляется от имени министерства иностранных дел или посольства. В ней излагаются различные вопросы: запрашиваются визы, сообщается о предоставлении агремана, направляется дипломатическая документация, например, консульский патент, информация представительского характера, например, приглашение на официальные приёмы по случаю национальных праздников, сообщения о визитах и поездках дипломатических работников в города и регионы Чешской Республики, об организации встреч с официальными лицами государства, об урегулировании административно-правовых вопросов и другие. Во вступительном комплименте чешских вербальных нот наименование отправителя и получателя указывается полностью: Diplomatický protokol Ministerstva zahraničních věcí České republiky projevuje úctu Velvyslanectví Ruské federace.

В отличие от российской практики, в заключении чешских вербальных нот обычно содержится не сокращённое, а полное название: Diplomatický protokol Ministerstva zahraničních věcí využivá této př́ležitosti, aby znovu ujistil Velvyslanectví Ruské federace v České republice o své hluboké úctě. При переводе с русского языка этот комплимент выглядит следующим образом: Ministerstvo využívá této př́ležitosti, aby znovu ujistilo Velvyslanectví o své hluboké úctě.

В ответной ноте министерства указывается ссылка на ноту посольства: $v$ souvislosti (v návaznosti) s nótou č. (datum, mésíc, rok) - в связи с нотой № (число, месяц, год).

В отличие от вербальной ноты, которая направляется одному адресату, циркулярная нота адресуется министерством иностранных дел всем дипломатическим миссиям, консульским учреждениям и международным организациям, аккредитованным в данной стране. Она может со- 
держать информацию об изменениях в организационной структуре или кадровом составе министерства, о назначении на должность новых сотрудников, изменении движения транспорта в связи с государственным визитом или, например, приглашение на презентацию программы председательства Чешской Республики в Вишеградской группе, которую устраивал заместитель министра иностранных дел Чешской Республики [4, с. 119-125]. Циркулярная нота также начинается и заканчивается протокольными формулами вежливости: Diplomatický protokol Ministerstva zahraničnich věcí České republiky projevuje úctu všem diplomatickým misím akreditovaným v Praze; Diplomatický protokol Ministerstva zahraničních věcí České republiky využívá této príležitosti, aby znovu ujistil diplomatické mise akreditované v Praze o své nejhlubší úctě [12, c. 314].

Как показывают приведённые примеры, комплименты выражают уважение адресату и призваны благожелательно настроить его при ознакомлении с содержанием ноты, которое изложено в смысловой части документа. Это могут быть проблемы двустороннего или многостороннего характера, в том числе связанные с новыми геополитическими реалиями, где позиции сторон не всегда совпадают.

Вместе с тем дипломатическая вежливость требует соблюдения такта и осторожности в оценке происходящих событий, описании фактов и отношения к ним, при согласовании позиций или закреплении договорённостей. А.Н. Ковалёв приводит в этой связи слова известного австрийского дипломата Х. Вильднера о том, что «стиль дипломатических документов должен отличаться прежде всего простотой и ясностью, умением «выбирать для каждого предмета единственное подходящее при данных обстоятельствах слово...», и в этом стиле «должна пульсировать внутренняя жизнь» [5, с. 136].

Язык дипломатических документов - это профессиональный язык, в котором соблюдаются все правила дипломатического этикета, не допускающие неопределённых или двусмысленных формулировок. Это достигается благодаря тому, что в текстах используются:

- нейтральные лексические единицы, лишённые императивной тональности, например: Uvítáme Vaše sdělení - Мы будем рады получить от Вас сообщение, вместо Sdělte nám - Сообщите нам; Máme čest požádat o souhlas - Имеем честь просить согласия, вместо Žádáme o souhlas - Просим согласия;

- этикетная лексика, включающая протокольные формулы вежливости и комплименты: projevit úctu - свидетельствовать уважение; ujistit o své úctè - принять уверения в своём уважении. В составе этикетной лексики встречаются также вышеупомянутые обращения-историзмы: Vaše Excelence, Jeho Veličenstvo;

- слова книжного, высокого стиля, которые придают документу торжественное звучание: ctěná mise - высокое представительство; zdvořilostní návštěva - визит вежливости; čestná stráž - почётный караул. При направлении документов, просьб, приглашений, сообщений наряду с выражением Máme čest используется Dovolujeme si (poslat, požádat, pozvat, sdělit);

- общепринятые термины и терминологические сочетания, характерные для языка дипломатической коммуникации: velvyslanec - посол, pověrení - аккредитация, protokolární pořadí - протокольное старшинство; в том числе термины латинского и французского происхождения: konzul, konvence, ataše, diplomacie, etiketa, причём некоторые из них сохранили своё первоначальное написание: status quo, persona non grata, casus belli, in claris, charge d'affaires;

- слова общелитературного языка, употребляющиеся в качестве терминов: protokol, nóta, nevměšování и другие, в том числе многозначные, например: pověřit (úkolem) - доверить, поручить (задание); pověrit (funkcí) - назначить (на должность); pověřit (zastupováním u cizí vlády) - аккредитовать; prijetí (eura jako cizíměny) - принятие (евро как национальной валюты); prijetí (velvyslance) приём (посла); zástupce ředitele - заместитель директора; právní zástupce - юрисконсульт, státní zástupce - прокурор, obchodní zástupce - торговый представитель, diplomatický zástupce - дипломатический представитель;

- чешско-русские паронимы и омонимы (“faux amis” - zrádní prátelé - «ложные друзья переводчика»), которые могут приводить к ошибкам, связанным с лексической интерференцией близкородственных языков, например: 


\begin{tabular}{|c|c|}
\hline mírový - мирный & мировой - světový \\
\hline pozdravit - поздороваться & поздравить - poblahoprát \\
\hline ústava - конституция & устав - ř́d, stanovy \\
ústav - институт & Устав OOH - Charta OSN \\
\hline řád - правила, распорядок & ряд - r̆ada \\
společenský řad & общественный строй \\
\hline platný - имеющий силу, действующий & платный - placený \\
\hline slovenský - словацкий & словенский - slovinský \\
& славянский - slovanský \\
\hline
\end{tabular}

- термины, обозначающие государственные символы и национальные памятники чешской культуры: státní znak - государственный герб, státní hymna - государственный гимн, státní pečet' государственная печать, которая ставится на международных договорах и верительных грамотах, prezidentská vlajka - президентский штандарт, korunovační klenoty - королевские коронационные регалии;

- лексические единицы, обозначающие названия государственных органов и дипломатических документов: Poslanecká sněmovna - Палата депутатов, diplomatická listina - список членов дипломатического корпуса, kabinetní list - письмо министра иностранных дел, которым аккредитуется временный поверенный в делах;

- названия отделов и департаментов Министерств иностранных дел Чехии и России, перевод которых, как правило, не содержится в двуязычных словарях: Tiskový odbor - Департамент информации и печати, Odbor rozvojové spolupráce - Департамент сотрудничества в интересах развития и другие.

Из приведённых примеров видно, что многие лексические единицы, обладающие национально-культурной семантикой, содержат в себе не только лингвистическую, но и экстралингвистическую информацию. Для их перевода необходимы фоновые знания, в том числе знания чешских реалий, например, Listina základních práv a svobod - Хартия основных прав и свобод. Она была принята как составная часть Конституции в декабре 1992 года накануне распада Чехословацкой Федерации, получившего название „Sametová revoluce“ («Бархатная революция»). Этот документ гарантирует экономические, социальные и культурные права и свободы всем гражданам, включая представителей национальных и этнических меньшинств.

Если обратиться к текстам правительственных документов, то здесь наблюдается использование официально-делового стиля литературного языка как языка чешской письменности. Он отличается значительной стабильностью, устоявшимися нормами и структурой. В нём используются лексико-грамматические конструкции, которые являются достоянием книжного языка и в устной речи практически не встречаются, например, деепричастные обороты, формы страдательного залога, некоторые устаревшие предлоги. Это также придаёт документу строгий, официальный характер: Prozkoumavše tuto smlouvu a vědouce, že Parlament ČR s ní souhlasil... - Изучив этот договор и принимая во внимание, что Парламент ЧР выражает согласие...; Ježto má být podepsán Prováděcí protokol... - Ввиду того, что должен быть заключён Исполнительный протокол... [4, c. 25].

Употребление деепричастий и форм описательного пассива не свойственно и чешскому обиходно-разговорному языку, однако в дипломатических текстах категории деепричастий настоящего времени используются, главным образом, в преамбулах международных договоров и документов, например, в Договоре о дружественных отношениях и сотрудничестве между Чехией и Россией от 1993 года: navazujíce na zásady - опираясь на принципы, zdưrazňujíce význam - подчёркивая значение; ř́díce se pravidly - руководствуясь нормами [4, c. 188]; в Венской конвенции о дипломатических сношениях: majíce na zřeteli - принимая во внимание, věříce - будучи убеждены, uvědomujíce si - сознавая [12, s. 318], а также в уже опоминавшейся Хартии основных прав и свобод: vkládajíc naděje - возлагая надежды, uznávajíc neporušitelnost - признавая нерушимость, vyjadřujíc vi̊li - выражая волю и т.д. [18, s. 200]. Формы страдательного залога используются также в ряде дипломатических документов, например, в экзекватуре: je udělen souhlas - дано согласие, 
в циркулярной ноте: byl jmenován na funkci - был назначен на должность, в консульском патенте: úkoly byly svěreny - задачи были возложены. Кроме того, использование таких грамматических форм характерно при ведении протоколов, записи деловых бесед и переговоров: otázky byly projednány - вопросы были обсуждены, dohoda byla podepsána - соглашение было подписано.

Следует отметить, что наряду с традиционными формами дипломатической коммуникации широкое распространение приобрели дипломатические документы, не имеющие строгих протокольных правил. Это заявления глав государств и правительств по случаю знаменательных событий, ответы на вопросы представителей общественности и средств массовой информации, выступления на дипломатических приёмах, международных форумах и пресс-конференциях [6, c. 62].

В зависимости от целевой аудитории они начинаются с обращения: Vážené dámy a pánové, Vážené velvyslankynè a velvyslanci, Vážené kolegyně a kolegové, Excelence. Здесь проявляется отличительная особенность чешского языка - образование соотносительных по роду пар слов мужского и женского рода, обозначающих профессии, занимаемые должности, выполняемые функции, например ředitel/ředitelka - директор (мужчина и женщина), poslanec - poslankyně (депутат), státní tajemník - státní tajemnice (госсекретарь). Однако в отдельных случаях существительное женского рода может иметь второе значение: diplomat/diplomatka: 1) женщина-дипломат, 2) папка, портфель; или только одно значение, которое не соотносится с первым: státník - государственный деятель, státnice (státní zkouška) - государственный экзамен. Та же родовая дифференциация присуща существительным, обозначающим мужские и женские фамилии: pan Zeman - paní Zemanová.

Суффикс ová добавляется и к иностранным фамилиям женского рода, например: kanclérka Angela Merkelová; ministr zahraničí EU, baronka Catherine Ashtonová; politička, předsedkyně Evropské komise Ursula von der Leyenová.

С началом демократических изменений в общественной жизни страны после 1989 года наблюдается демократизация языка и стиля публичных выступлений, меняется и риторика дипломатического общения. Президент Чехословацкой Республики и первый президент Чешской Республики Вацлав Гавел в своей новогодней речи 1 января 1990 года обратился к гражданам Чехословакии: Milí spoluobčané [10, s. 1] - Дорогие сограждане вместо традиционного Vážené soudružky a soudruzi, которое обычно использовалось в годы коммунистического правления (слово soudruh/soudružkaтоварищ воспринималось как обращение к членам Коммунистической партии).

Выступления государственных деятелей и дипломатических представителей, обращённые как к своему народу, так и к народам других стран, характеризуются наличием общественно-политической лексики, профессиональных терминов и клише (konstruktivní dialog - конструктивный диалог, pri̊zkum veřejného mínění - изучение общественного мнения, v zájmu stability a bezpečnosti в интересах стабильности и безопасности), а также эмоционально окрашенной лексики (důstojná oslava - достойное торжество, trnitá cesta - тернистый путь, vzdát čest/hold - отдать честь, воздать почести). Широко используется в последние годы заимствованная лексика, главным образом из английского языка, а также из некоторых других языков, причём многие заимствования носят интернациональный характер: leader/lídr, mainstream, médium, manipulace, ratifikace, sankce, pandemie, multilaterální и другие. Такая лексика семантически однородна и стилистически нейтральна, что позволяет однозначно воспринимать содержащуюся в тексте информацию. Министр иностранных дел Чешской Республики Томаш Петршичек в своей речи при вступлении в должность в октябре 2018 года подчёркивал, что внешняя политика Чехии должна состоять из 3К: kontinuální, koherentní, konsensuální [9, s. 1].

Среди морфологических признаков таких текстов можно выделить употребление следующих частей речи:

- отглагольных имён существительных со значением действия: dodržování (zásad) - coблюдение (принципов), šírení (informace) - распространение (информации), dosážení (jednoty) достижение единства; а также обозначающих абстрактные явления и понятия, как правило, в тех случаях, когда они образованы от глаголов совершенного вида, например: spiknutí - заговор, přesvědčení - убеждение, nadšení - восторг и другие; 
- $\quad$ лексических единиц, отражающих важные исторические события (так называемых «событийных слов»): Mnichovská dohoda, Charta 77, srpnové události, listopadová revoluce;

- качественных имён прилагательных в превосходной степени: nejúspěšnější integrační uskupení - самое успешное интеграционное объединение, nejakceschopnější organizace - самая дееспособная организация, nejvýznačnější předchůdce - самый выдающийся предшественник;

- инфинитива в различных синтаксических конструкциях: prohlásit nezávislost - объявить независимость, čelit hrozbám - противостоять угрозам, prosazovat své zájmy - отстаивать свои интересы; в том числе в составе будущего времени: Budeme přispivat/podporovat/usilovat - Мы будем содействовать/ поддерживать/ прилагать усилия;

- глаголов в 1-м лице множественного числа для выражения позиции, коллективного мнения, побуждения к действиям или оценки происходящих событий: Pokládáme za nutné - Считаем необходимым, Vyzýváme vládu - Призываем правительство, Vysoce si vážíme/ceníme - Мы высоко ценим; при этом местоимение ту не употребляется, и в подобных словосочетаниях в русском языке оно также не является обязательным и часто опускается;

- $\quad$ предлогов и предложно-падежных форм в составе устойчивых языковых оборотов: $v$ této souvislosti - в этой связи, u př́ležitosti - по случаю, podle ustanovení Smlouvy - согласно положению Договора, причём семантические объёмы некоторых предлогов в чешском и русском языках не всегда совпадают, сравните: jmenovat do funkce - назначить на должность, odvolat z funkce - освободить от должности.

Для синтаксической структуры предложений характерно использование сослагательного наклонения для выражения приветствия (Dovolte, abych Vás přivital - Разрешите Вас приветствовать), благодарности, просьбы, пожелания, сообщения: rád bych poděkoval/poprosil/poprál/oznámil, а также оборотов типа jsem rád/jsem velmi rád/jsem nesmírně potěšen.

Высказывания в таких текстах строятся с ориентацией на 1-е лицо, на говорящего, что обуславливает более широкое использование личных конструкций: To nesmíme pripustit - Этого нельзя допустить; Zde si můžete o tom podrobně prečíst - Здесь можно об этом подробно прочитать. Сочетание модальных глаголов smět, moci с инфинитивом означает допустимость и возможность действия.

При выражении различных коммуникативных намерений чехам не свойственны резкие высказывания, громкие призывы, тем более в ультимативной форме. Смягчить категоричный тон призваны личные кондициональные конструкции с использованием модальных глаголов: Měli bychom se na tom aktivně pedílet - Нам следовало бы/следует в этом активно участвовать. Здесь проявляется сдержанная тональность, которая исключает требование или принуждение, а, напротив, выражает пожелание или рекомендацию. Что касается грамматической категории необходимости и долженствования с модальным глаголом musit/muset, то её употребление также определяется целевыми установками. В качестве примера приведём высказывание министра иностранных дел ЧР Томаша Петршичка из выше упомянутой речи в октябре 2018 года.: "Zahraniční politika musí odrážet naše hodnoty“- Внешняя политика должна отражать наши ценности. В Европейском союзе "musime vystupovat konstruktivně a srozumitelně", в Североатлантическом альянсе "musíme potvrdit roli cenného a divvěryhodného spojence", "transatlantickou vazbu musíme rozvíjet a posilovat", "musíme být aktivní zejména v rámci $E U$ a OSN” [9, s. 2].

В этих высказываниях утверждаются ценностные ориентиры чешской внешней политики, подчёркивается необходимость совместных действий в рамках ЕС и НАТО, готовность выполнять обязательства, вытекающие из договорных отношений, а неоднократное повторение глагола долженствования оказывает эмоциональное воздействие на слушателей, формируя представление о приоритетных направлениях профессиональной деятельности политиков и дипломатов на ближайшую перспективу.

Иначе воспринимаются побудительные действия, которые выражаются формами повелительного наклонения в 1-м лице множественного числа. Они не являются такими категоричными как приказы, требования, запреты, а содержат побуждение к совместным действиям в виде просьбы, совета, убеждения, призыва. В известном новогоднем обращении Вацлав Гавел выступил с призывом восстановить само понятие политики. При этом он ссылался на первого чехословацкого 
президента Т.Г. Масарика, который в основе государственной политики видел глубокий духовный и нравственный смысл. Zkusme obnovit..., učme sami sebe i druhé..., nemylme se... - Давайте попробуем восстановить..., давайте учиться и учить других..., давайте не будем ошибаться...

В своей речи Вацлав Гавел перефразировал известные слова Отто фон Бисмарка о том, что «политика есть искусство возможного» [2, с. 1]. Učme sami sebe i druhé, že politika nemusí být jen uměním možného..., ale že může být i uměním nemožného [10, s. 3]. В первой части предложения содержится утверждение, что политика не должна быть (nemusí být) только искусством возможного, а во второй части допускается возможность, что она может быть (může být) и искусством невозможного.

Такие стилистические и смысловые оттенки в речи позволяют расставить необходимые акценты и привлечь внимание к содержанию всего выступления, которое и сегодня по-прежнему высоко оценивается современниками экс-президента.

Побуждение, призыв встречается также в описательных конструкциях императива, состоящего из модальной частицы at' и презентной формы глагола в 3-м лице единственного числа. Предшественник В. Гавела на посту президента Густав Гусак закончил свою новогоднюю речь 1 января 1989 года словами: “At' vzkvétá naše vlast!” - Пусть процветает наша родина! По такому же грамматическому принципу построено известное в годы социализма воззвание At' žije nerozborné př́telství! - Да здравствует нерушимая дружба!

На приведённых примерах прослеживается существующая в чешском языке закономерность между функциями высказывания и средствами их выражения. Содержание одного и того же дипломатического текста, переданное различными лексико-грамматическими средствами, может восприниматься по-разному, однако изложение фактического материала в нём всегда отличается конкретностью и логической обоснованностью. Так, заместитель председателя Парламента Чешской Республики в своём выступлении на приёме в российском посольстве по случаю Дня России в 2017 году высказал серьёзные возражения в адрес западных СМИ, обвинявших Россию во вмешательстве в выборные процессы ряда стран. Он назвал эти обвинения необоснованными и бездоказательными (neodůvodněné a nepodložené), используя при этом выразительное славянское слово с яркой стилистической окраской, не характерное для литературного языка, balamutit - баламутить [4, с. 162]. В речи звучали такие лексические единицы, которые выполняли функции информации и убеждения, как, например, hybridní válka - гибридная война, hackerské zásahy - вмешательство хакеров, útoky masmédií - информационные атаки, protiruské sankce - антироссийские санкции, что помогало выстроить в языковом сознании слушателей сразу целую цепочку новых понятий о происходящих событиях.

Следует отметить, что в дипломатическом тексте может быть изложена информация, не всегда приятная или даже неприемлемая для принимающей стороны, однако языковые формулы такого послания должны оставаться корректными и уважительными по отношению к представителям другого государства. В качестве примера приведём комментарий российского посольства в Праге в связи с демонтажем памятника советскому маршалу И.С. Коневу, которое произошло в апреле 2020 года. Это, безусловно, вызвало негативную реакцию российского руководства, однако, несмотря на всю остроту сложившейся ситуации, комментарий дипломатического представительства отличался сдержанной тональностью, что никак не могло унизить или оскорбить позицию другой стороны. Чёткое и продуманное изложение доводов сопровождалось использованием эмоционально-экспрессивных лексических средств: neprátelský krok - недружественный шаг, hluboké rozhořčení - глубокое возмущение, porušení závázků Smlouvy - нарушение обязательств Договора и других. Использование таких формулировок, раскрывающих смысл всего документа, помогло опытным дипломатам сохранить дипломатические приличия и вместе с тем заявить решительный протест - rázný protest и предупредить об ответных действиях - př́slušná reakce [13].

Такое умелое построение текста делает его выразительным и убедительным, что позволяет воспринимать события достоверно и, более того, поддерживать «кредит доверия конкретной дипломатической школы и её представителей» [6, с. 66].

Анализ содержания дипломатических документов показывает, что, наряду с вопросами двустороннего характера, в них затрагиваются и важные международные вопросы, даётся оценка 
достигнутого уровня отношений между странами, намечаются перспективы дальнейшего сотрудничества, в том числе в экономической сфере. Особенно это стало заметно после вступления Чехии в НАТО (1999 г.) и Евросоюз (2004 г.), что обусловило новые направления во внутренней и внешней политике страны. Это нашло своё отражение в словарном составе языка. Появились новые лексические единицы и терминологические сочетания, такие как: unijní stanovisko - позиция ЕС, přerozdělovací kvóty - квоты по распределению мигрантов, smiřovací snahy - усилия по примирению, kybernetické útoky - кибернетические атаки и другие, которые требуют точной передачи смыслового значения, как и сокращения названий представительств ряда крупных чешских компаний, работающих на российском рынке, например: CzechTrade - Агентство по поддержке торговли, CzechInvest - Агентство по поддержке иностранных инвестиций.

Интересно отметить в этой связи курьёзный факт, который произошёл в процессе обсуждения проекта новой европейской конституции. При переводе её текста на 9 языков новых государствчленов ЕС возникли разногласия относительно принципов правописания общеевропейской валюты «евро». Согласно Конституции, было установлено только одно единственное название euro, причём отклонения в национальных языках не допускались. В то время как «старые члены» ЕС этому принципу подчинились, некоторые «новые члены» выразили своё несогласие, ссылаясь на то, что в Словении, например, принято название evro, в Литве - euras, в Латвии - eiro, а в Венгрии euroo. Языковую проблему эти страны возвели на уровень государственного престижа, даже суверенитета, хотя, как отмечает чешский журналист Милан Сыручек, дискуссии о суверенитете могли вызвать другие статьи текста конституции, среди которых вопрос о названии и написании общей валюты казался бы самым простым [16, s. 46].

Это не первый случай, когда неоднозначный перевод вызывал политические дискуссии. Именно на геополитической основе возник в бывшей Чехословакии спор о том, как переводить название Федеративной Республики Германии. Несмотря на то, что это было официальное название государства в чешском переводе Договора о взаимных отношениях между ЧССР и ФРГ от 1973 года, в повседневной жизни его нельзя было употреблять, поскольку оно означало, что Федеративная Республика является государством всей Германии, тогда как в то время существовала и ГДР. Исходя из этих соображений, следовало писать Германская Федеративная Республика, объясняя это с лингвистической точки зрения тем, что чешский язык не использует в подобных наименованиях генитив. Что касается европейской валюты, то венгров, например, возмутил тот факт, что Брюссель пытается им диктовать, как следует на венгерском языке писать слово euro. Ведь греки, по их утверждению, тоже пользуются исключением, хотя бы потому, что они не пишут латиницей [16, s. 47].

Всё это свидетельствует о том, что язык дипломатической коммуникации, подчиняясь определённым закономерностям стиля и правилам дипломатического этикета, не является неизменным, а испытывает влияние тех общественно-политических, экономических, научно-технических, социально-культурных и иных процессов, которые происходят в современном мире. Возрастают требования к профессионализму во всех сферах человеческой деятельности. Это в полной мере относится к языку как средству налаживания и развития контактов с зарубежными партнёрами. Как отмечал постоянный представитель РФ при ООН В.И. Чуркин: «Владение иностранным языком - непременное условие обеспечения эффективной деятельности любого российского дипломатического представительства, залог успешной работы каждого дипломата» [7, с. 70].

Следовательно, для составления дипломатических текстов на чешском языке и перевода их на русский язык, адекватно отражающего язык оригинала, необходимо овладеть языком и стилем дипломатического общения на профессиональном уровне. Это ставит перед исследователями и преподавателями высшей школы задачу дальнейшего изучения дипломатической стилистики на базе оригинальных текстов, а также правил протокола и этикета межгосударственного общения между Чешской Республикой и Российской Федерацией. Работа в этом направлении позволит продолжить создание современных учебных пособий нового поколения по языку профессии с целью подготовки высококвалифицированных специалистов в этой области.

(C) Давлетшина Н.В., 2021 


\section{Список литературы}

1. Ахманова О.С. Словарь дипломатических терминов. М.: Советская энциклопедия, 1966. 606 с.

2. Бисмарк О. Политика есть искусство возможного. М.: Центрполиграф, 2015. 160 с.

3. авранек Б.З. Задачи литературного языка и его культура. Пражский лингвистический кружок. М.: Прогресс, 1967. 412 c.

4. Давлетшина Н.В. Дипломатический протокол и дипломатическая корреспонденция на чешском языке. М.: МГИМОУниверситет, 2019.212 с.

5. Ковалев А.Н. Азбука дипломатии. М.: Международные отношения, 1984. 246 с.

6. Кузьмин Э.Л. Протокол и этикет дипломатического и делового общения. М.: Юридический колледж МГУ, 1996. 382 с.

7. 195 лет Службы языковой подготовки МИД России. М.: Ключ-С, 2018. 260 с.

8. Широкова А.Г. Чешский язык/ А.Г. Широкова, В.Ф. Васильева, А.М. Едличка А. М.: МГУ, 1990. 314 с.

9. Фонды Посольства РФ в Праге. 2020, 10 с.

10. Havel Václav. Projev k občanům na Nový rok 1.ledna 1990. [Electronic resource] - URL:http// www.vaclavhavel.cz. (Дата обращения: 14.12.2020)

11. Hubiner V. Enciklopedie diplomacie. Praha: Libri, 2006. $192 \mathrm{s.}$

12. Gullová S. Mezinárodní obchodní a diplomatický protokol. Praha: Grada, 2013. $336 \mathrm{~s}$.

13. Komentáŕ Velvyslanectví Ruské federace v České republice v souvislosti s demontáží pomníku maršála I.S.Koněva v Praze. [Electronic resource] - URL: https://czech.mid.ru/3.04.2020. (Дата обращения: 24.04.2020)

14. Krejčí O. Mezinárodní politika. Praha: Ekopress, 2007. 752 s.

15. Outrata V. Mezinárodní právo veřejné. Praha: Orbis, 1960. $646 \mathrm{~s}$.

16. Syruček M. Diplomacie v negliže. Praha: Mladá fronta, 2005. 384 s.

17. Trávniček F. O jazykovém slohu. Praha: SPN, 1953. 69 s.

18. Ústava České republiky. Listina základních práv a svobod. Olomouc: Olomouc, s.r.o. 2005. 264 s.

\section{References}

1. Akhmanova, O.S. Slovar' diplomaticheskikh terminov [Vocabulary of diplomatic terms] Moscow: Sovietskaia entsiklopedia, 1966. $606 \mathrm{p}$.

2. Bismark, O. Politika est' iskusstvo vozmozhnogo [Politics is the art of the possible] Moscow: Tsentrpoligraf, 2015. $160 \mathrm{p}$.

3. Gavranec, B.Z. Zadachi literaturnogo iazyka i ego kultura. Prazhskiy lignvisticheskiy kruzhok [Aims of the literary language and its culture. The Prague linguistic club]. Moscow: Progress, 1967. 412 p.

4. Davletshina, N.V. Diplomaticheskiy protocol i diplomaticheskaia korrespondentsia na cheshskom iazyke [Diplomatic protocol and diplomatic correspondence in Czech]. Moscow: MGIMO-Universitet, 2019. $212 \mathrm{p}$.

5. Kovaliov, A.N. Azbyka diplomatii. [ABC of diplomacy]. Moscow: Mezhdunarodnye otnoshenia, 1984. 246 p.

6. Kuz'min, E.L. Protocol i etiket diplomaticheskogo i delovogo obshchenia [Protocol and etiquette of the diplomatic and business communication]. Moscow: Iuridicheskiy kolledzh MGU, 1996. 382 p.

7. 195 let sluzhby iazikovoj podgotovki MID Rossii [195 years to the Language Training Service of the Russian MFA] Moscow: Kliuch-C, 2018. 260 p.

8. Shirokova, A.G., Vasil'eva V.F., et al. Cheshskiy iazyk. [The Czech language] Moscow: MGU, 1990. 314 p.

9. Fondi Posolstva RF v Prage [The funds of the Russian Embassy in Prague]. 2020, 10 p.

10. Havel Václav. Projev k občanům na Nový rok 1.ledna 1990, www.vaclavhavel.cz. (Accessed 25.10.2020)

11. Hubiner, V. Enciklopedie diplomacie. Praha: Libri, 2006. $192 \mathrm{s.}$

12. Gullová, S. Mezinárodní obchodní a diplomatický protokol. Praha: Grada, 2013. 336 s.

13. Komentár Velvyslanectví Ruské federace v České republice v souvislosti s demontáží pomníku maršála I.S. Koněva v Praze, https:// czech.mid.ru/3.04.2020 (Accessed 24.04.2020)

14. Krejčí, O. Mezinárodní politika. Praha: Ekopress, 2007. $752 \mathrm{~s}$.

15. Outrata, V. Mezinárodní právo veřejné. Praha: Orbis, 1960. $646 \mathrm{~s}$.

16. Syruček, M. Diplomacie v negliže. Praha: Mladá fronta, 2005. $384 \mathrm{~s}$.

17. Trávniček, F. O jazykovém slohu. Praha: SPN, 1953. 69 s.

18. Ústava České republiky. Listina základních práv a svobod. Olomouc, 2005. $263 \mathrm{~s}$.

\section{Сведения об авторе:}

Давлетшина Нелли Васильевна - кандидат экономических наук, доцент кафедры языков стран Центральной и Юго-Восточной Европы МГИМО-Университета МИД России. Сфера научных интересов: современная языковая ситуация в Чехии, методика преподавания языка профессии, проблемы перевода официальных документов. E-mail: nv109273@icloud.com 


\section{About the author:}

Davletshina Nelli Vasilievna - Ph.D in Economics, Associate Professor of the languages of the Central and South-West Europe of the MGIMO-University. The area of scientific interests: the current language situation in the Czech Republic, methods of teaching professional language, translation of official documents.

E-mail:nv109273@icloud.com 